\title{
Como se tornar um bolsista da Fundação Rockefeller: trajetórias de médicos do Instituto Oswaldo Cruz em formação na Universidade Johns Hopkins (1919-1924)
}

Ricardo dos Santos Batista*

Luiz Otávio Ferreira ${ }^{* *}$

\section{RESUMO}

Este texto tem como objetivo analisar a trajetória de médicos brasileiros que estudaram no Instituto Oswaldo Cruz e, posteriormente, foram financiados pela Fundação Rockefeller para estudar na Johns Hopkins University. As fontes utilizadas foram correspondências trocadas entre os escritórios da agência filantrópica no Brasil e nos Estados Unidos, coletadas no Rockefeller Archive Center, uma tese de doutoramento, um relatório médico e fontes orais. A análise desses documentos auxiliou a compreender os conflitos, negociaçóes e impasses na seleção dos bolsistas enviados aos Estados Unidos, a formação na universidade norte-americana e o seu retorno ao Brasil, entre 1919 e 1924. Trajetórias de formação profissional internacional também foram marcadas por questôes regionais e locais, e por trocas de conhecimentos sobre saúde pública.

Palavras-chave: Fundação Rockefeller; Instituto Oswaldo Cruz; formação profissional; saúde internacional; filantropia norte-americana.

DOI: http://dx.doi.org/10.1590/2237-101X02204708

Artigo recebido em 23 de março de 2020 e aceito para publicação em 27 de julho de 2020 .

* Professor da Universidade do Estado da Bahia, Programa de Pós-Graduação em História - Campus II, Alagoinhas/BA - Brasil. E-mail: kadobatista@hotmail.com. ORCID: https://orcid.org/0000-0002-7959-5929.

** Pesquisador da Fundação Oswaldo Cruz / Departamento de Pesquisa, Rio de Janeiro/RJ - Brasil. E-mail: ulume2@gmail.com. ORCID: https://orcid.org/0000-0002-7512-7343.

Esta pesquisa foi financiada pelo Conselho Nacional de Desenvolvimento Científico e Tecnológico - CNPq, processo 150091/2017-6. 


\section{How to become a Rockefeller Foundation Scholar: trajectories of Oswaldo Cruz Institute doctors who trained at Johns Hopkins University (1919- 1924)}

\section{ABSTRACT}

This text analyzes the trajectory of Brazilian doctors from the Oswaldo Cruz Institute who secured Rockefeller Foundation funding to study at Johns Hopkins University between 1919 and 1924. The article is based on material from the Rockefeller Archive Centersuch as correspondence between the philanthropic agency's offices in Brazil and United States - a doctoral thesis, a medical report, and oral histories. These sources help illuminate the conflicts, difficulties, and negotiations that occurred during the selection of scholars, their training in North America, and their return to Brazil. Regional and local issues and exchanges of knowledge about public health also characterized the experience of international professional training.

Keywords: Rockefeller Foundation; Oswaldo Cruz Institute; professional qualification; international health; American philantropy.

\section{Cómo convertirse en un becario de la Fundación Rockefeller: trayectorias de médicos del Instituto Oswaldo Cruz en formación en la Universidad Johns Hopkins (1919-1924)}

\section{RESUMEN}

Este texto tiene como objetivo analizar la trayectoria de médicos brasileños que estudiaron en el Instituto Oswaldo Cruz y, posteriormente, fueron financiados por la Fundación Rockefeller para estudiar en la Universidad Johns Hopkins. Las fuentes utilizadas fueron correspondencias intercambiadas entre las oficinas de la agencia filantrópica en Brasil y Estados Unidos, coleccionadas en el Rockefeller Archive Center, una tesis doctoral, un informe médico y fuentes orales. El análisis de esos documentos ayudó en la comprensión de los conflictos, negociaciones impases en la selección de becarios enviados a Estados Unidos, la formación en la Universidad norteamericana y su regreso a Brasil, entre 1919 y 1924. Trayectorias de formación profesional internacional también fueron marcadas por cuestiones regionales y locales, y por intercambios de conocimientos sobre salud pública.

Palabras clave: Fundación Rockefeller; Instituto Oswaldo Cruz; formación profesional; salud internacional; filantropía norteamericana. 
Este texto tem como objetivo analisar o percurso realizado por médicos brasileiros bolsistas da Fundação Rockefeller nas primeiras décadas do século XX, a partir das trajetórias de personagens como Olympio da Fonseca Filho e Antônio Luis Cavalcanti de Albuquerque de Barros Barreto. Eles estudaram no Curso de Aplicação do Instituto Oswaldo Cruz (IOC), que teve papel relevante na carreira de profissionais da saúde pública do país, alguns deles posteriormente enviados para estudar na América do Norte.

Para analisarmos a trajetória dos médicos bolsistas da Fundação Rockefeller, nos apropriamos, de modo específico e limitado, das noçôes de trajetória e de campo científico (CATANI et al., 2017, p. 354-356, p. 68-70). O que pretendemos descrever são os movimentos por entre posiçôes institucionais e científicas que estavam sendo criadas (trajetória) em um momento específico da dinâmica histórica do campo médico-científico brasileiro, marcado pela intensa reconfiguração dos modelos institucionais e das práticas científicas. Vamos observar como se deu a construção de trajetórias médicas na emergência do novo tipo de medicina e de médicos que surgia com a institucionalização da intersecção entre a medicina de comunidade (saúde pública) e a medicina no laboratório (microbiologia, bacteriologia e parasitologia).

Antes da Organização Mundial da Saúde ser fundada, em 1948, a International Health Divison (IHD) da Fundaçấo Rockefeller foi a agência filantrópica mais importante do mundo no trabalho em saúde pública. Desde o seu surgimento foram-lhe atribuídos diferentes nomes: International Health Comission (IHC), entre 1913 e 1916; International Health Board (IHB), de 1916 a 1927; e, de 1927 até o seu fechamento, em 1951, funcionou como IHD (FARLEY, 2004, p. 2). Desde o início, os membros do IHB seguiram os princípios filantrópicos de John D. Rockefeller, milionário norte-americano que investiu na agência internacional com o dinheiro oriundo da exploração, refino e comércio de petróleo e defendeu que a filantropia não poderia ser confundida com a caridade. Ela deveria ser encarada como um investimento oferecido a agências governamentais e não a indivíduos, com duraçáo limitada para não se tornar dependência, destinada a organizaçôes comprometidas com a continuidade do trabalho quando o auxílio terminasse (FARLEY, 2004, p. 3-5).

A Universidade Johns Hopkins, em Baltimore, foi a primeira instituição de ensino no mundo financiada pela Fundação Rockefeller e questionou o modelo de educação médica vigente nos Estados Unidos até a primeira década do século XX. No final do século XIX, a saúde pública era institucionalizada nos departamentos de saúde das cidades ou estados norte-americanos, mas poucos profissionais tinham treinamento especializado na área. Eles geralmente recebiam cargos de meio período, remunerados por patrocínio político, eram promovidos ou despedidos com base em suas alianças políticas e amizades pessoais. A maioria dos funcionários da saúde pública possuía formação médica, mas alguns eram engenheiros, outros advogados, químicos e biólogos (FEE, 2016, p. 1-2).

Havia pouco consenso em relação ao tipo de conhecimentos necessários para a prática em saúde pública. Nesse sentido, a publicação do relatório produzido pelo filósofo e educa- 
dor Abraham Flexner sobre o ensino médico nos Estados Unidos contribuiu para transformar a organização da educação em saúde. Ele apontou as deficiências na formação médica e defendeu a ênfase na experiência prática em hospitais de ensino, professores contratados em tempo integral e estudantes familiarizados com laboratórios (CUETO; PALMER, 2016, p. 126). Apoiada pela agência filantrópica internacional, a Johns Hopkins funcionou como um centro de formação de oficiais de saúde pública que recebeu profissionais de todo o mundo.

Segundo Marinho (2013, p. 104), o objetivo das escolas de saúde pública apoiadas pela Rockefeller era formar mão de obra para suprir operaçôes relativas às campanhas de prevenção e quadros para a infraestrutura de manutenção do sistema de saúde pública, bem como treinar professores, estudantes e profissionais qualificados dedicados à questáo. A estratégia se apoiava na premissa de que essas instituiçóes formariam "elementos-chave" para o sistema de saúde pública. Mais tarde a noção de elementos-chave evoluiu para o conceito de sementes iniciais, designando a vocação da Fundação para apoiar financeiramente bolsistas ou instituiçôes criteriosamente selecionadas que pudessem propagar o modelo de ciência da instituição.

No que diz respeito à América Latina, foram oferecidas bolsas e auxílios a médicos e estudantes para visitar os Estados Unidos ou estudar, assim como para promover visitas de cientistas norte-americanos ao continente (CUETO; PALMER, 2016, p. 135; CUETO, 1994). Isso contribuiu para a expansão de um estilo de medicina especializado em saúde pública, distinto da tradição da medicina clínica e hospitalar de origem francesa, e para ampliação da influência cultural norte-americana nos países latino-americanos. Após o retorno ao seu país de origem, os bolsistas continuavam a ser acompanhados pelo escritório de Nova Iorque, com anotaçóes em cartôes de bolsistas que descreviam as posiçôes ocupadas por eles.

Embora historiadoras já tenham dado ênfase à trajetória de alguns bolsistas brasileiros (Cf. CAMPOS, 2013; MARQUES; SILVEIRA, 2015), é necessário analisar de forma mais circunstanciada os conflitos, negociaçôes e impasses presentes no processo de seleção e na formação internacional desses profissionais, assim como as contribuiçôes dadas à saúde brasileira quando do seu retorno ao país.

Para essa pesquisa, foram utilizados como fontes um relatório da Subsecretaria de Saúde e Assistência Pública da Bahia, uma tese de doutoramento em Saúde Pública, uma entrevista de Olympio da Fonseca Filho ao Centro de Pesquisa e Documentação de História Contemporânea do Brasil (CPDOC) e correspondências trocadas entre membros dos escritórios da Fundação Rockefeller nos Estados Unidos e no Brasil. Essas correspondências foram enviadas por Lewis Hackett, diretor regional associado do IHB no Brasil, e por outros membros do staff da Fundação Rockefeller. Hackett se formou na Faculdade de Medicina de Harvard e passou a fazer parte da IHC em 1914. Nos anos seguintes, organizou e dirigiu o Departamento de Ancilostomíase no Panamá, trabalhou na Guatemala e Honduras, onde a Rockefeller também atuou (FARIA, 1995, p. 116). A sua experiência contribuiu para 
administrar questôes importantes como a indicação e o envio dos bolsistas aqui apresentados. Ainda no Brasil, mensagens foram trocadas com Carlos Chagas, diretor do Departamento Nacional de Saúde Pública (DNSP).

Entre os outros interlocutores, é possível destacar Clifford Wells, representante do IHB nos Estados Unidos; Victor George Heiser, que a partir de 1915 trabalhou como diretor do IHB no Oriente; e Richard Pearce, professor de Patologia e de Investigação Médica na Pensilvânia, designado como conselheiro da IHC no campo da Educação Médica que, em 1919, tornou-se diretor da Divison of Medical Education (DME) (FOSDICK, 2017, p. 105). Além destes, destaca-se Wickliffe Rose, que teve atuação importante no início das açôes da Fundaçáo Rockefeller, em 1909 se tornou secretário executivo e, posteriormente, primeiro diretor do IHB.

\section{A formação profissional no Instituto Oswaldo Cruz: o Curso de Aplicação}

Entre a segunda metade do século XIX e o início do século XX, a medicina se reconfigurou e se diversificou em termos de instituiçóes práticas. Willian Bynum (2011), especifica três estilos de medicina que surgiram e coexistiram nesse período: medicina hospitalar (clínica e patológica); medicina na comunidade (higiene e saúde pública) e medicina no laboratório (bacteriológica, também chamada de "medicina experimental"). Essa inovação ajudou a transformar a compreensão sobre as doenças e seus agentes etiológicos, especialmente pelo surgimento da bacteriologia. Nesse contexto, instituições auxiliaram na formação de médicos e pesquisadores a partir da experimentação em laboratórios, como ocorreu com o IOC, no Rio de Janeiro.

De acordo com Azevedo e Ferreira (2012), a instituição implantou pioneiramente uma tradição de ensino médico-científico (medicina no laboratório) em medicina tropical e microbiologia, inaugurando no Brasil um novo padrão que englobava formaçáo teórica e treinamento prático de pesquisadores e especialistas. Esse projeto se deu pelas mãos de Oswaldo Cruz que, ao assumir a Direção da Saúde Pública no Rio de Janeiro, investiu no então chamado Instituto Soroterápico, criado no contexto da chegada da peste bubônica ao Brasil (BENCHIMOL; TEIXEIRA, 1993). Com o intuito de desenvolver um centro de pesquisa nos moldes do Instituto Pasteur, na França, o médico solicitou verbas ao legislativo, o que não foi aprovado. Mas, com recursos da sua pasta, iniciou a edificação de um conjunto arquitetônico sofisticado para abrigar novos laboratórios, novas linhas de pesquisa, a fabricação de mais soros e vacinas e o ensino da microbiologia (BENCHIMOL et al., 2001, p. 54).

Durante o período em que Oswaldo Cruz esteve na direção do Instituto, entre 1902 e 1917, houve duas fases na organização do ensino: uma em que as atividades de ensino e pesquisa não eram tão bem delimitadas e, outra, na qual o ensino se apresentou de forma 
mais definida (CORTES, 1993, p. 132). A segunda fase se iniciou após a promulgação do Decreto n. 1802, de 14 de dezembro de 1907. O aumento do número de interessados e a complexidade alcançada pelos trabalhos de pesquisa foram utilizados como justificativa para que o aprendizado se estruturasse sob a forma do Curso de Aplicação, o que também atrairia pesquisadores de outros países: "Entre 1908 e 1935, quinhentas pessoas inscreveram-se no curso; no período entre 1911-1949 foram aprovados 275 alunos" (AZEVEDO; FERREIRA, 2012, p. 584).

No trabalho desenvolvido no IOC havia liberdade para que os estudantes escolhessem seus objetos de pesquisa, visto que Oswaldo Cruz queria que os integrantes do seu "jardim de infância", todos estudantes com menos de 30 anos, tivessem autoconfiança para desenvolverem trabalhos originais (BENCHIMOL; TEIXEIRA, 1993, p. 20). Muitos deles vislumbravam a possibilidade de se tornarem nomes reconhecidos nacionalmente pela pesquisa, pelos estudos desenvolvidos em medicina tropical, pela descoberta de patologias e vetores, em um contexto no qual cientistas do IOC realizavam investigaçóes nos sertóes brasileiros na segunda década do século XX (BATISTA, 2019a, p. 812).

Entre os estudantes da turma de 1912 (Figura 1) e 1913 do Curso de Aplicação, é possível encontrar personalidades que se envolveram com o projeto da Fundação Rockefeller, introduzido no Brasil ainda em 1916. Médicos como João de Barros Barreto, Heráclides Cézar Souza de Araújo e Antônio de Barros Barreto trilhariam os caminhos da agência filantrópica, financiados como bolsistas. Eles deixaram o Brasil por um ou dois anos, para se dedicar a uma formação em saúde pública, retornando, posteriormente, para ocupar cargos de chefia sanitária no país.

O IOC, especialmente através do Curso de Aplicação, ofereceu aos estudantes (inicialmente exclusivamente acadêmicos de medicina ou médicos recém-formados) os conhecimentos teóricos e práticos básicos que os habilitavam a atuar em laboratórios de pesquisa e/ou em pesquisa de campo conforme o padrão estabelecido nos Estados Unidos, especificamente na Universidade Johns Hopkins. Embora fosse determinante para as autoridades sanitárias brasileiras que esses estudantes se dedicassem ao Curso de Saúde Pública da universidade norte-americana, alguns conseguiram dispensa em disciplinas após realizarem provas de conhecimento prático e mostrarem ter o nível de conhecimentos exigido, o que os possibilitou realizar mais atividades em laboratório. A relaçáo de Carlos Chagas com o IOC contribuiu para que esses jovens médicos, alguns deles já inspetores do DNSP, fossem recomendados como bolsistas. 
Figura 1: Alunos do Curso de Aplicação de 1912

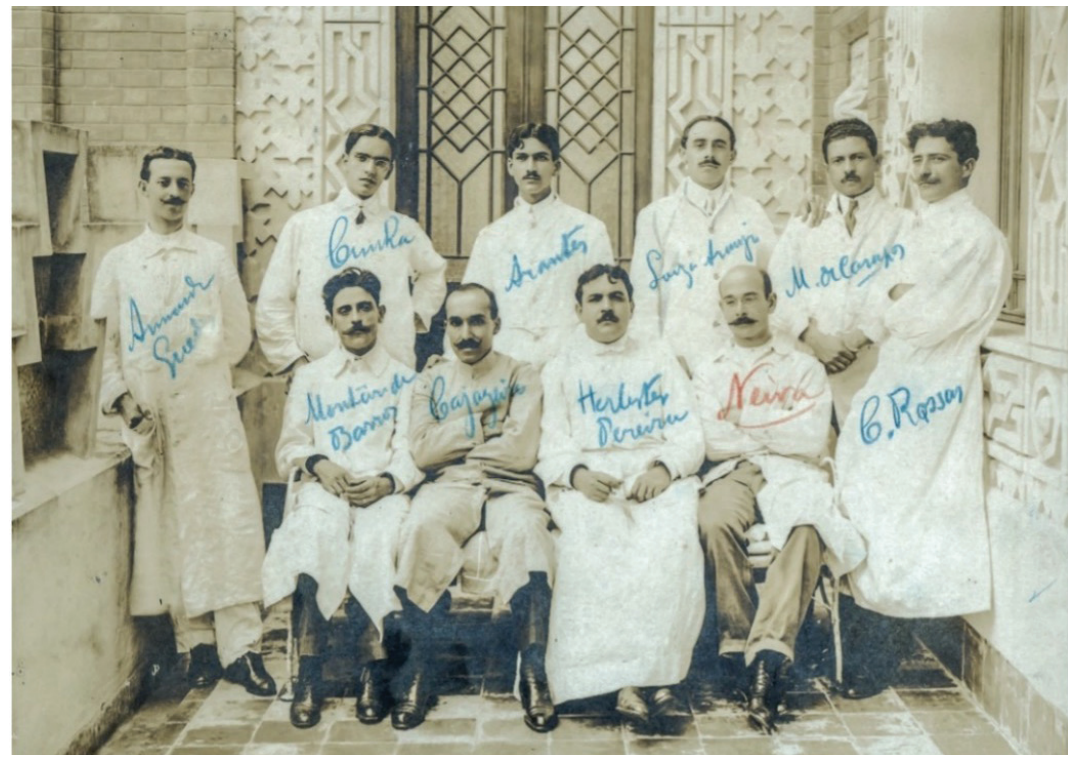

Fonte: Instituto Oswaldo Cruz (IOC) / Acervo Casa de Oswaldo Cruz

Antes de analisar o percurso internacional realizado por esses profissionais, é preciso discutir brevemente a funcionalidade do Comitê Consultivo que indicava os candidatos.

\section{O Comitê Consultivo e o caso do tracoma}

Uma das questóes que gerou grande número de correspondências entre os membros dos escritórios da Fundação Rockefeller de Nova Iorque e do Brasil diz respeito à seleção dos candidatos a bolsistas nos Estados Unidos. Para tentar garantir que o IHB se guiasse por critérios universalistas e evitar a influência de favoritismos na seleção, foi criado o Brazilian Advisory Committee on Traveling Scholarships (CASTRO SANTOS; FARIA, 2003, p. 63) que era composto por Carlos Chagas, Vital Brazil e Alexandrino de Moraes Pedroso.

Quando o mineiro Carlos Pinheiros Chagas, primeiro bolsista brasileiro, foi enviado aos Estados Unidos, em 1917, havia expectativas em relação ao perfil dos candidatos posteriores, mas ainda não havia critérios bem definidos de seleção. Em 1921, duas questóes eram fundamentais para a concessão de bolsas: se o campo selecionado pelo candidato era importante no momento e se a posição que o bolsista ocuparia quando retornasse ao Brasil teria autoridade e suficiência para justificar os gastos do IHB (CASTRO SANTOS; FARIA, 2003 p. 63).

Naquele mesmo ano, Lewis Hackett solicitou de Clifford W. Wells, do escritório de Nova Iorque, ideias em relação aos procedimentos a serem utilizados na seleção. O próprio 
Hackett propôs começar a escolha cedo o bastante para que os profissionais partissem para os Estados Unidos o mais tardar em julho, e, em outubro, quando o ano letivo iniciasse, estivessem adaptados e compreendessem melhor a língua inglesa para um melhor aproveitamento da instrução nos primeiros meses ${ }^{1}$.

Nos anos iniciais da política de bolsas, após organizado o Comitê, os membros não possuíam um status permanente. Em 26 de setembro de 1919, Carlos Chagas informou mudanças ocorridas nas vidas pessoal e profissional de seus integrantes, o que poderia ser considerado pelos norte-americanos como empecilho para que continuassem a compor o órgão. Alexandrino Pedroso ingressou como professor na Faculdade de Medicina e Cirurgia de São Paulo e Vital Brazil se mudou de São Paulo para Niterói, no Rio de Janeiro². Brazil deixou o Instituto Butantan, solicitou aposentadoria e fixou residência em outro estado sob o pretexto de cuidar da saúde, no momento em que a instituiçáo se transformou em uma fábrica de soros, vacinas e medicamentos, e Arthur Neiva queria dotá-la de orçamento para poder disputar com o IOC (BENCHIMOL; TEIXEIRA, 1993, p. 161-162). Para Chagas essas modificações demandavam que um novo nome fosse incluído no Comitê, o de Samuel Taylor Darling, primeiro diretor do Instituto de Higiene de Sáo Paulo e, além disso, expressou a disposição de Pedroso em deixar o grupo caso a Fundaçáo Rockefeller achasse conveniente.

Quase três meses depois, a discussão sobre a composição do Comitê continuava. Hackett defendia que, além de Darling, ele mesmo também o integrasse. Se queixava da presença de decisóes políticas na seleção de bolsistas e garantia que não permitiria mais essa prática. Ele sofreu pressóes do escritório de Nova Iorque, que o questionou sobre a forma como os candidatos eram selecionados e usou como exemplo dois bolsistas: um não conseguia bom desempenho nos estudos e o outro não chegou aos Estados Unidos com a antecedência suficiente, o que demonstrava, para o IHB, um fracasso do Comitê. Foi proposto a Richard Pearce que, a partir de então, houvesse dois membros em Sáo Paulo e três no Rio ${ }^{3}$.

A análise de Hackett sobre a atuação do Comitê indicava que o órgão brasileiro era utilizado apenas para nomear os bolsistas. Ele acreditava que os integrantes náo estavam em busca dos candidatos adequados para enviar aos Estados Unidos, mas de cargos nos serviços públicos que pareciam necessitar de "um desenvolvimento acelerado em linhas modernas".

Essa hipótese não pode ser descartada visto que, na segunda década do século XX, médicos e pesquisadores brasileiros desenvolveram viagens a lugares distantes dos grandes centros urbanos e produziram relatórios que registraram as condiçóes de vida da populaçáo interiorana, os hábitos, as técnicas, a mentalidade, associando os aspectos socioeconômicos,

\footnotetext{
${ }^{1}$ HACKETT para Wells, 4 jan. 1921a.

${ }^{2}$ CHAGAS para Rose, 26 set. 1919.

${ }^{3}$ HACKETT para Pearce, 17 dez. 1919, p. 2.

${ }^{4}$ Traduçáo dos autores. No original: "an anaccelerate development along modern lines". HACKETT para Wells, 4 jan. 1921b, p. 1.
} 
culturais e ambientais às questóes sanitárias (THIELEN et al., 2002, p. 7). Como fruto dessas investigaçôes, o chamado movimento sanitarista difundiu uma imagem do Brasil como "imenso hospital e um vasto sertão", o que contribuiu para despertar uma consciência sanitária entre as elites brasileiras (HOCHMAN, 1998). Possivelmente influenciados por esse contexto, os membros do Comitê atuavam de forma pragmática ao dar prioridade para a formação de profissionais que já trabalhavam na saúde, não tinham uma formação específica na área que lideravam e nem sempre eram considerados profissionais "brilhantes".

Hackett considerava, ainda, que o manuseio das bolsas era a parte mais delicada do seu trabalho, devido à dificuldade de lidar com algumas autoridades brasileiras, e criticava um corporativismo dos médicos locais, o que inviabilizava a recomendação de um candidato baseada apenas em sua capacidade técnica:

[...] O Comitê Consultivo foi, penso eu, um fracasso. Nunca atuou como um comitê, mas como indivíduos. O Dr. Vital Brazil não participa mais de suas atividades e, portanto, os candidatos sáo selecionados pelo Dr. Pedroso, caso em que o Dr. Chagas sempre concorda ou pelo Dr. Chagas, caso em que o Dr. Pedroso inevitavelmente concorda. Eles vivem em centros médicos separados [Sáo Paulo e Rio de Janeiro], que nada têm em comum e cada um age sozinho em sua própria esfera. Ocasionalmente, algum estranho de fora toma a iniciativa de sugerir um candidato, a quem muitas vezes tenho enorme dificuldade em eliminar se por acaso ele náo tiver valor 5 .

Era notável o desconforto em recusar uma indicação feita por uma personalidade política ou social, porque, em alguns casos, soaria como ofensivo. Em alguns momentos as indicaçôes causaram tensão entre os membros do Comitê e isso pode ser percebido em um episódio específico no qual Alexandrino Pedroso ameaçou renunciar, devido à decisão do IHB de não financiar uma bolsa de estudo sobre tracoma. O médico havia se formado nos Estados Unidos, em 1904, na Universidade da Pensilvânia, intermediou os primeiros contatos entre Arnaldo Vieira de Carvalho e Richard Pearce nos acordos para o apoio da Fundação Rockefeller à Faculdade de Medicina e Cirurgia de São Paulo e se destacou nas relaçôes científicas e institucionais com a agência norte-americana (MARINHO, 2013, p. 127), motivo pelo qual provavelmente foi convidado a compor o Comitê. Caso ele desistisse de participar, o órgão consultivo seria desabilitado e, junto com Chagas, se tornaria um assessor não oficial.

\footnotetext{
${ }^{5}$ Tradução dos autores. No original: "The Advisory Committee has, I think, been a failure. It has never acted as a comittee but as individuals. Dr. Vital Brasil no longer takes part in its activities and the candidates are therefore selected either by Pedroso in which case Dr. Chagas always agree or by Dr. Chagas in which case Dr. Pedroso inevitably concurs. They live in medial centers which have nothing in common and each acts alone in his own sphere. Ocasionally some distingished outsider takes it upon himself to suggest a candidate, whom I often have enormus difficulty in eliminating if he happens to be worthless". HACKETT para Wells, 4 jan. 1921b, p. 2.
} 
Quando ainda se investigava o perfil esperado do candidato que receberia bolsa para estudar tracoma, o IHB sugeriu que um médico de Sáo Paulo fosse beneficiado e Francisco Salles Gomes Junior foi considerado como a melhor opção possível para a vaga, em um momento em que trabalhava como diretor do Saneamento Rural ${ }^{6}$. Mas disputas foram travadas em relação à bolsa.

O Governo de São Paulo, por outro lado, indicou Mário Pernambuco, médico que posteriormente dirigiu o combate à ancilostomíase no estado. Esse fato causou uma celeuma em relação ao profissional que efetivamente seria enviado aos Estados Unidos: "quando abordamos o assunto de treinar um homem em Tracoma para o governo de São Paulo nós não tínhamos a mais fraca ideia do que o governo tinha em mente para apontar o Dr. Mario Pernambuco para a posição agora ocupada por Salles Gomes"7. A Fundação Rockefeller receava que o governo brasileiro interpretasse o envio de Gomes Junior como benefício próprio (já que ele foi o escolhido pela agência filantrópica) e inviabilizou a bolsa.

Alexandrino Pedroso passou a alegar que estava constrangido devido às negociaçóes que fez com o Governo de São Paulo, sob a crença de que a bolsa seria ofertada. Os paulistas já haviam realizado duas grandes tentativas de controlar a doença com comissóes que geraram um custo muito elevado e Pedroso defendia ser um erro organizar um terceiro ataque em grande escala, sem uma orientação devida ${ }^{8}$. Ele argumentou com o Secretário do Interior sobre a necessidade de formar um homem para estudar o tracoma antes de iniciar uma nova investida, mas se sentiu desamparado pela agência filantrópica com o cancelamento.

Não se pode descartar a possibilidade de a Fundaçáo Rockefeller ter julgado que Pedroso utilizava a bolsa com fins políticos, o que ia contra as diretrizes da instituição. Esse episódio indica que o Comitê podia funcionar como um espaço de disputas, e que, apesar de ser composto por nomes de destaque da saúde brasileira, não era um órgão que discutia efetivamente políticas de envio de bolsistas, mas agia com membros que atuavam de forma isolada. Isso pôde ser observado no ano de 1921, quando Antônio de Barros Barreto foi indicado como bolsista do IHB.

\section{A seleção de bolsistas e o envio aos Estados Unidos}

Em fevereiro de 1919, Hackett recebeu quatro pedidos de bolsas, com profissionais aprovados pelo Comitê Consultivo brasileiro: Eurico Vilella, assistente de Carlos Chagas; João

\footnotetext{
${ }^{6}$ HACKETT para Rose, 5 ago. 1920.

7 Tradução dos autores. No original: "when we broached the subject of training a man in Trachoma for the Government of São Paulo we had not the faintest idea that the Government had it in mind to appoint Dr. Mario Pernambuco to the position now occupied by Dr. Salles Gomes". HACKETT para Rose, $31 \mathrm{dez}$. 1920, p. 1.

${ }^{8}$ HACKETT para Rose, 31 dez. 1920, p. 2.
} 
Florêncio Salles Gomes, irmão de Francisco Salles Gomes e assistente de Vital Brazil no Instituto Butantan; Afrânio Pompilio Bastos do Amaral, da mesma instituição; e Olympio da Fonseca Filho, definido como um jovem brilhante homem, bem fundamentado em parasitologia, ex-diretor de campo do Board no Brasil e que foi recomendado sem reservas pelo próprio Hackett ${ }^{9}$.

Três dos profissionais tinham em comum a passagem pelo IOC. Eurico Vilella foi convidado por Oswaldo Cruz, em 1912, para trabalhar na instituição e integrou a Comissão de Profilaxia e Assistência Médica enviada a Lassance para iniciar os estudos clínicos sobre a doença de Chagas. João Florêncio Salles Gomes e Olympio da Fonseca Filho estudaram com Antônio de Barros Barreto na turma de 1913 do Curso de Aplicação do IOC, sendo que os dois últimos também trabalharam no projeto da Fundação Rockefeller na década de 1910 (BATISTA, 2019a).

Exceto Eurico Vilella, que teve problemas de saúde e não aceitou a bolsa ${ }^{10}$, os candidatos foram confirmados no mês de abril. A decisão do IHB foi facilitada porque os médicos não eram casados, o que não elevaria o valor do financiamento e sugeria disponibilidade maior de tempo para o estudo.

Os imprevistos que ocorriam na seleção dos bolsistas ajudavam a definir os procedimentos adotados por Lewis Hackett no Brasil. Com o intuito de agilizar o processo, ele os informou que podiam começar a traçar os planos para viajar em junho para Nova Iorque, mesmo que a sua aprovação formal ainda não tivesse chegado do exterior, o que ocorreria até final de maio ${ }^{11}$. Mas os membros do staff da Fundação Rockefeller não apoiaram essa atitude e sugeriram que, diante da incerteza em relação à decisão da Diretoria, ele evitasse oferecer informaçóes dessa natureza em negociações futuras para não haver mal-entendidos. Embora naquele caso a posição fosse favorável, isso poderia não ocorrer com todos os nomes que fossem indicados ${ }^{12}$.

A programação das bolsas para 1919 foi modificada pela morte de João Florêncio Gomes, de pneumonia após gripe, no final de maio, e pelo direcionamento de Fonseca Filho para o trabalho contra a febre amarela na Bahia, devido ao estado alarmante da doença. Apenas Amaral parecia estar disponível para ser enviado, o que contribuía para a especulação de um novo nome, o de José Alves de Castilho Jr., diretor de Saúde Pública de Minas Gerais, que Hackett acreditava ser capaz de desenvolver um bom programa no seu retorno, com cargo de destaque no estado ${ }^{13}$. Contudo, a bolsa de Afrânio Amaral foi suspensa porque ele teria colocado a Fundação Rockefeller em situação de constrangimento, numa disputa política de São Paulo.

\footnotetext{
${ }^{9}$ HACKETT para Rose, 26 fev. 1919.

${ }^{10}$ HACKETT para Rose, 3 abr. 1919.

${ }^{11}$ HACKETT para Rose, 7 abr. 1919.

${ }^{12}$ HEISER para Hackett, 22 mai. 1919, p. 1-2.

${ }^{13}$ HACKETT para Rose, 5 jun. 1919.
} 
O médico desempenhava um papel relevante no centro de pesquisa paulista. Diante da dificuldade de Arthur Neiva em encontrar um substituto para Vital Brazil e com o déficit dos pesquisadores que o acompanharam, a direção do Butantan foi exercida por Afrânio do Amaral, que permaneceu interino até 6 de setembro de 1921 (BENCHIMOL; TEIXEIRA, 1993, p. 168). Como um grupo desejava removê-lo de suas funçôes no Instituto, ficou a impressão de que a Rockefeller atuava conscientemente como instrumento em suas mãos. Por esse motivo, ele só viajou para os Estados Unidos em 1922, enquanto Fonseca Filho solicitou o início dos estudos em 1920, com a bolsa que já havia sido aprovada ${ }^{14}$.

Se os nomes de João Florêncio Gomes, Afrânio do Amaral e Olympio da Fonseca Filho foram pensados e indicados com antecedência, o mesmo não ocorreu com Barros Barreto, em 1921. Diante dos conflitos que existiam no Comitê, em muitos momentos a opiniáo de Carlos Chagas parecia ter maior relevância. Talvez suas indicaçôes fossem consideradas mais confiáveis pelo IHB, por ser diretor do DNSP. Naquele ano, por exemplo, os membros da Fundação Rockefeller dependeram da sua disponibilidade para indicar alguém, sem realizar consulta aos outros membros do Comitê.

Em maio, os candidatos brasileiros ainda não haviam sido escolhidos. Hackett tentou fazer com que Carlos Chagas indicasse pelo menos dois jovens promissores do DNSP para realizarem o Curso de Higiene na Universidade Johns Hopkins, mas o médico afirmou que só podia fazer isso quando retornasse de sua viagem aos Estados Unidos, por volta de julho. Com o intuito de poupar tempo e permitir que os indicados chegassem em Nova Iorque em agosto, o homem de campo da Rockefeller pediu a Wickliffe Rose o consentimento do Board para que, após a indicação de Chagas, ele mesmo referendasse os nomes ${ }^{15}$, procedimento que foi aprovado ${ }^{16}$. Isso fugia do que se esperava como norma adequada para uma seleção e flexibilizava orientaçôes dadas a Hackett anteriormente pelo próprio IHB $^{17}$, demonstrando que mesmo com a tentativa de estabelecer dispositivos padróes na seleção, os contextos interferiam na sua organização.

Clifford Wells e Carlos Chagas se reuniram em Boston, conversaram e decidiram os candidatos para o ano de 1921. Hackett foi informado sobre a indicação de Gustavo Lessa e de Enugdio de Mattos e, como suplentes, Armínio Fraga e Areia Leão. Assim, prosseguiu com os arranjos definidos, devendo informar a Rose ou Wells sobre os dois selecionados e apresentar os dados biográficos dos candidatos ao Comitê Executivo ${ }^{18}$. Esse trabalho deveria ser realizado antes de abordá-los diretamente com o assunto ${ }^{19}$, em uma nítida preocupação com o perfil dos candidatos.

\footnotetext{
${ }^{14}$ HACKETT para Heiser, 11 mar. 1920.

${ }^{15}$ HACKETT para Rose, 6 mai. 1921.

${ }^{16}$ ROSE para Hackett, 27 mai. 1921.

${ }^{17}$ HEISER para Hackett, 7 jan. 1920.

${ }^{18}$ SECRETARY ASSISTANCE para Hackett, 6 jun. 1921.

${ }^{19}$ HACKETT para Rose, 14 jun. 1921.
} 
A indicação de Gustavo Lessa agradou a Hackett, que já havia pensado em seu nome. Ele era diretor de um dos postos de Profilaxia Rural no Distrito Federal e gostaria de estudar administração em Saúde Pública, com ênfase em bem-estar infantil. Entretanto, tinha como impedimento um exame que seria realizado em outubro, momento em que as aulas iniciariam nos Estados Unidos, para conseguir uma posição permanente no DNSP. Por isso, solicitou o adiamento da viagem para o ano seguinte ${ }^{20}$. As açôes desenvolvidas pelo novo órgão estatal, criado em 1919, a partir das reivindicaçóes do movimento sanitarista (Cf. HOCHMAN, 1998), mobilizaram um grande número de médicos, sendo que aqueles que ainda não haviam se efetivado vislumbraram a possibilidade de alcançar estabilidade e de serem reconhecidos como funcionários federais por meio de concurso, oportunidade almejada por Lessa.

Segundo Hackett era difícil conseguir "o homem mais capaz para ir aos Estados Unidos" naquele ano, devido à recente reorganização do DNSP, visto que era difícil para o governo brasileiro poupar um homem capacitado naquele período construtivo. Contudo, não estava disposto a mandar um "homem medíocre pelo simples fato de preencher a cota que o Brasil poderia esperar" ${ }^{21}$, o que era reiterado pelo escritório de Nova Iorque ${ }^{22}$. O segundo candidato era Armínio Fraga, subinspetor da Divisão de Doenças Venéreas e Lepra do DNSP, que também havia estudado microbiologia, parasitologia e imunologia no IOC, concluindo no ano 1919 (FRAGA, s.d.). Como já era funcionário público, ele precisava apenas de uma licença por um ou dois anos.

O mais provável é que, devido ao concurso para o DNSP, Gustavo Lessa tenha desistido e Carlos Chagas propôs um novo nome rapidamente. Em 24 de agosto, o diretor do DNSP informou o envio de uma carta de recomendação do médico Antônio Luis Cavalcanti de Albuquerque de Barros Barreto para Diretoria da Fundação Rockefeller ${ }^{23}$.

\section{A formação dos bolsistas em Johns Hopkins}

Armínio Fraga e Antônio de Barros Barreto chegaram em Nova Iorque em 6 de setembro e, no dia seguinte, ligaram para o escritório da Rockefeller. Clifford Wells afirmou que os membros do IHB estavam positivamente impressionados no escritório com os dois médi$\cos ^{24}$. Embora houvesse indicação prévia de que Fraga cursaria Higiene em Johns Hopkins,

\footnotetext{
${ }^{20}$ HACKETT para Wells, 26 jul. 1921.

${ }^{21}$ Tradução dos autores. No original: "It is difficult to get the ablest man to go to the States this year owing to the recente re-organization of the Public Health Department. The really capable mana are difficult to spare at this constuctive period. I am not willing to send medíocre men simply for the sake of filling out the quota which Brazil might be expected to furnish”. HACKETT para Wells, 26 jul. 1921, p. 1-2.

${ }^{22}$ READ para Hackett, 18 ago. 1921.

${ }^{23}$ WELLS para Strode, 24 ago. 1921.

${ }^{24}$ WELLS para Hackett, 8 set. 1921.
} 
ele afirmou que náo necessitava de tal curso e preferia dedicar todo o ano ao estudo do controle venéreo, da lepra e do câncer. Wells recomendou que ele se matriculasse no primeiro trimestre enquanto consultaria Carlos Chagas sobre a alteração do estudo. Barros Barreto, por outro lado, demostrava interesse em se inscrever no curso regular, mas também desejava realizar um ou dois cursos sobre radioterapia e terapia de raios-X, o que também seria avaliado por Chagas ${ }^{25}$.

Naquele momento, a Universidade Johns Hopkins admitia dois tipos de estudantes. Os que desejavam se doutorar e os chamados estudantes especiais. Nessa última condição eram enquadrados os que não cumpriam todos os pré-requisitos para o programa de pós-graduaçáo e os que queriam apenas passar breves períodos de tempo na escola em um ou dois cursos (FEE, 2016, p. 74). Três graus eram oferecidos: doutor em Saúde Pública, doutor em Ciências e Higiene e bacharel em Higiene. O diploma de doutorado em Saúde Pública era possível a graduados de uma faculdade de medicina aprovada ou classe A, que também possuíam diploma em artes ou ciências como evidência de uma educação liberal. Os alunos egressos da Universidade Johns Hopkins podiam se integrar a esse programa após três anos de treinamento médico e todos os candidatos deveriam ter passado um veráo de trabalho prático em um serviço organizado de saúde pública.

Na primeira turma, iniciada em $1^{\circ}$ de outubro de 1918, foram selecionados quatro estudantes de doutorado, dois candidatos a bacharéis em Higiene e dois alunos especiais. Entre os candidatos a doutorado, três foram enviados pelo IHB: John Ferrel, Francisco Borges Vieira e Geraldo Horácio de Paula Souza. Os dois últimos foram levados de São Paulo, onde a Fundação Rockefeller pretendia abrir uma escola de Saúde Pública para a América Latina (Cf. MARINHO, 2013). O grupo de estudantes era pequeno nos primeiros anos, mas logo começou a aumentar, sendo que em 1921 havia 23 estudantes; em 1922, 96; e em 1923, 123, números explicados pelo rápido crescimento de alunos especiais (FEE, 2016, p. 76).

Destaca-se que também estudaram como bolsistas personalidades como Fred Soper e Frederick Russell, que mais tarde se tornariam, respectivamente, autoridade mundial no combate à febre amarela e diretor da IHD. Aquela formaçáo era considerada importante tanto pela Fundaçáo Rockefeller, que encontrou um lugar de aperfeiçoamento do seu próprio quadro e de quadros profissionais de diferentes lugares do mundo, quanto, no caso dos brasileiros, para Carlos Chagas, pois era através dela que se esperava especializar os médicos que atuariam no país.

Em relação às diferenças da formação em Johns Hopkins em comparação a outras universidades no mesmo período, Olympio da Fonseca Filho enfatizou a restrição no número de alunos, em 1920, o que evidenciava o seu alinhamento às recomendaçôes do Relatório Flexner:

${ }^{25}$ WELLS para Hackett, 8 set. 1921. 
Em Johns Hopkins havia um alto nível, o ensino era realmente superior e, quase todos os alunos já eram doutores em ciências ou coisas parecidas. Já a Faculdade Estadual de Universidade de Maryland era a escola para a pequenada, para a mocidade. Lá o curso era completamente diverso [...] e embora houvesse limitação de matrícula, era dado da maneira que fosse possível. Em Johns Hopkins nunca havia mais de 20 alunos no Curso de Dermatologia, enquanto que Maryland havia 70, 80 alunos (FONSECA FILHO, 2010, p. 18).

Quando consultado sobre o desejo de Armínio Fraga de não frequentar a universidade, Chagas decidiu que ele deveria realizar o curso da Johns Hopkins. Embora existissem assuntos elementares dos quais o médico já tivesse muito conhecimento, o diretor do DNSP considerava que a maior parte do curso seria novo e até mesmo em assuntos como bacteriologia ele provavelmente teria um treinamento que não havia recebido em nenhum outro lugar. Se Fraga fosse dispensado dos temas que já dominava, poderia usar o tempo para outros cursos ou trabalhos práticos nos quais estivesse interessado e, ao final da formação, teria tempo suficiente para estudar o controle venéreo. Já em relação a Barreto, não foi feita nenhuma objeção a qualquer trabalho adicional que ele fosse capaz de realizar em paralelo à formação na universidade ${ }^{26}$.

Em relação ao itinerário formativo realizado em Baltimore, Barros Barreto estudou engenharia sanitária, estatísticas 1 e 2, epidemiologia nos dois primeiros trimestres e obteve o grau de doutor em Saúde Pública no terceiro trimestre (BARRETO, s.d.). Fraga estudou doenças venéreas/hospital, administração em Saúde Pública e deixou incompleto o curso de epidemiologia (FRAGA, s.d.). Em 5 de abril de 1922, Wells escreveu para Hackett ansioso para saber a sua opinião sobre os médicos brasileiros. Naquele momento, Fraga estava no Hospital Memorial em Nova Iorque para estudar métodos modernos de terapia para o câncer. Mais tarde estudaria o mesmo assunto com William Duane, do Havard and Hutington Cancer Hospital ${ }^{27}$.

Os dois médicos pediram autorização para ir à França se especializar, respectivamente, no problema do controle das doenças venéreas e em eletro, hidroterapia e helioterapia ${ }^{28}$. $\mathrm{O}$ IHB não achava necessária uma viagem para estudar doenças venéreas, já que nos Estados Unidos havia muitas oportunidades para isso. Em relação ao tema de Barros Barreto, questionava se isso era de suma importância para o Brasil, de fato que justificasse a viagem ${ }^{29}$.

A recusa do IHB em financiar estudos na França, justificada pela existência de campo de estudo nos Estados Unidos na área solicitada por pelo menos um dos candidatos, demonstrava preferência da instituição pela medicina praticada naquele país. Assim, foi apresentada uma proposta aos médicos de receberem o dinheiro da passagem e irem à Europa sob suas

\footnotetext{
${ }^{26}$ HACKETT para Wells, 14 out. 1921.

27 WELLS para Hackett, 5 abr. 1921.

${ }^{28}$ WELLS para Hackett, 5 abr. 1921.

${ }^{29}$ WELLS para Hackett, 5 abr. 1921.
} 
próprias expensas. Armínio Fraga afirmou não ter condiçôes de fazer isso, enquanto Barros Barreto optou por seguir para o velho mundo. Apesar de não realizar a concessão, Wells considerava que eles estavam recebendo excelente treinamento nos Estados Unidos ${ }^{30}$.

No início da Johns Hopkins, todos os alunos de doutorado eram obrigados a publicar suas dissertaçôes, mas à medida em que o número de alunos aumentava e o American Journal of Hygiene foi inundado com textos de estudantes, esta regra foi considerada impraticável (FEE, 2016, p. 74). Como fruto do estudo realizado no Hospital Johns Hopkins, Barros Barreto desenvolveu uma tese intitulada $O$ efeito da exposição de raios $X$ no metabolismo. ${ }^{31}$

Ele destacou a inexistência de trabalhos anteriores que analisassem o efeito dos raios-X em corpos de animais em repouso, visto que todos destacavam a exposição de corpos com câncer ou leucemia (BARRETO, 1922, p. 747). Utilizou aves como cobaias porque elas permaneciam quietas durante os experimentos, em contraposição aos ratos que dificultavam a obtenção de bons resultados. Seis aves foram irradiadas com o objetivo de investigar a sua taxa de consumo de oxigênio antes e depois da radiação, com a utilização do aparato de Meyer (Figura 2).

Figura 2 - Aparato de Meyer, utilizado por Barros Barreto

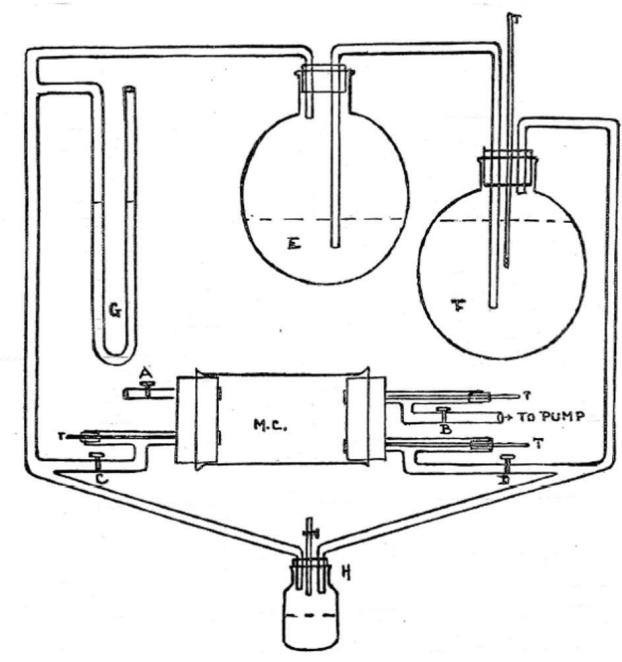

Fonte: Barreto (1922, p. 748)

Destaca-se a liberdade para que a tese de doutorado em Saúde Pública na Johns Hopkins fosse elaborada a partir de interesses pessoais do médico, demonstrados desde que chegou aos Estados Unidos em relaçáo aos raios-X. Mas isso não significa que Barros Barreto não tenha dialogado com outros conhecimentos atuais para aquele momento e que estiveram presentes na sua atuação quando retornou ao Brasil, como a medicina tropical. No ano de 1922, ele

\footnotetext{
${ }^{30}$ WELLS para Hackett, 1 jun. 1922.

${ }^{31}$ Tradução dos autores. No original: "The effect of $x$-ray exposure on metabolism". 
produziu textos e os leu nas disciplinas cursadas em Johns Hopkins: Sanitary significance of mosquitoes and other insects, em Engenharia Sanitária e Seasonal distribution of deaths by diarrhéa under two years at diferents latitudes in the United States of America (ALB, 1947, p. 6).

Assim como ocorreu com outros bolsistas, também realizou visitas a departamentos de saúde norte-americanos para realizar observaçóes in loco. Recebeu cartas de apresentação para o Hospital Montefiore, para o Blythewood Sanitarium Greenwich e para o Hospital Naval, no Brooklyn, além de instituiçóes relativas a Higiene Industrial (BARRETO, s.d.).

Embora geralmente se enfatize a influência dos métodos norte-americanos sobre os médicos brasileiros e a contraposiçáo à tradição clínica francesa, de grande influência no Brasil entre fins do século XIX e início do século XX, é possível afirmar que houve trocas de conhecimento entre médicos brasileiros e norte-americanos, e que aspectos da medicina clínica auxiliaram os últimos no desenvolvimento das suas atividades. Olympio da Fonseca Filho destacou a dificuldade que os médicos de Johns Hopkins tinham de acessar outras leituras que não as publicadas em inglês e que orientavam a sua prática. A maior parte dos professores não lia outro idioma. Alguns poucos conheciam o alemão por terem estudado na Alemanha. Então o brasileiro, com a bagagem intelectual que carregava, ajudou o doutor Bayne-Jones mais de uma vez:

O Bayne-Jones tinha dois casos de exinomicose e não sabia como lidar com o material e eu lhe disse o que fazer: "você faz assim: aspira uma gota de pus com a pipeta e goteja sobre o fixador. O pus endurece, fixa e você trata como uma peça histológica e corta no micrótomo". Foi o que ele fez, apesar de ter ficado muito espantado com aquilo. De outra vez ele teve uma dificuldade, que não me lembro mais o que era, e também dessa vez lhe disse como resolver. Então, ele virou-se para mim e perguntou: “onde você aprendeu isso?” Respondi que havia sido nos livros franceses. Então ele pediu-me que fizesse uma lista de livros franceses (FONSECA FILHO, 2010, p. 20).

\section{De volta ao Brasil: o acompanhamento dos bolsistas}

A formação em Johns Hopkins preparava os bolsistas para uma atuação ampla no campo da Saúde Pública, embora cada um deles se dedicasse a um tema específico de estudo. Disciplinas como estatística e engenharia sanitária auxiliaram na administração pública e em projetos de saneamento realizados por médicos como Geraldo Horácio de Paula Souza, Antônio de Barros Barreto e Fernando de Freitas e Castro em São Paulo, Bahia e Rio Grande do Sul (Cf. CAMPOS, 2002; BATISTA, 2017; KORNDÖRFER, 2013).

Não seria possível realizar aqui uma avaliação profunda sobre o impacto da formação dos bolsistas nas açóes desenvolvidas em seu retorno ao Brasil e das especificidades dos projetos realizados em cada unidade federativa e instituiçóes contempladas com bolsas. No 
caso de Barros Barreto, que conduziu a Reforma Sanitária da Bahia entre 1924 e 1930, destacam-se, entre outras realizações, a criação da Subsecretaria de Saúde e Assistência Pública, independente administrativa e financeiramente, subordinada diretamente ao governador Francisco Marques de Góes Calmon (BARRETO, 1927, p. 3). A partir da sua experiência de formação, o médico incluiu nesse documento a possibilidade de enviar funcionários da saúde baiana para estudar em outros estados e países, assim como levar médicos de outros locais para formar profissionais na Bahia.

Barros Barreto também propagou técnicas de educação e propagandas sanitárias aprendidas nos Estados Unidos (BATISTA, 2019b). Ele criou a Diretoria de Demografia e Educação Sanitária, dividida em três seções: estatística demógrafo-sanitária, educação sanitária e cadastro e recenseamento; e a Diretoria de Engenharia Sanitária, composta pelos setores de construçôes, águas, esgotos, obras de hidrografias sanitárias, lixo e tombamento dos próprios pertencentes à repartição sanitária (BARRETO, 1927, p. 5-6). Serviços sanitários relativos a outros assuntos que interessaram ao médico no exterior, como a Higiene Industrial e a Profilaxia da Lepra e das Doenças Venéreas, foram inseridos na Diretoria de Epidemiologia e Profilaxia Geral.

Com a transformação da Subsecretaria em Secretaria de Saúde e Assistência Pública, em 1927, investiu na transformação das delegacias de saúde que existiam em Salvador em Centros de Saúde, o que também pode ser observado como influência da Fundação Rockefeller após observar como Geraldo Horácio de Paula Souza operacionalizava os Centros de São Paulo (VALENTE, 1927).

Em seu retorno ao país, assim como outros bolsistas, o médico manteve contato estreito com a Fundação Rockefeller. Em 1926, solicitou a assinatura de periódicos como o Journal of Preventive Medicine, para continuar atualizado das tendências da medicina ${ }^{32}$. Outros médicos solicitaram a construção de laboratórios e bibliotecas, na ampliação do conhecimento e metodologias norte-americanas no país.

A Fundação Rockefeller acompanhou a trajetória dos seus bolsistas e registrou informações como a posição que ocuparam no serviço público ao longo dos anos, em fichas individuais. Com o intuito de realizar um levantamento de dados mais sistemático, em 1924, George Strode enviou questionários e coletou informaçóes sobre as suas vidas. Cinco deles não responderam até aquele momento (Simeão Bomfim, Fernando de Freitas e Castro, Olympio da Fonseca Filho, Jorge Dutra Fragoso e José da Costa Pinto), mas foi apresentada uma lista completa de todos os aprovados para estudar no exterior, assim como aqueles aprovados para a Faculdade Medicina e Higiene de São Paulo, no Brasil: ${ }^{33}$

\footnotetext{
${ }^{32}$ ROLLIN para Janney, 30 dez. 1926.

${ }^{33}$ Os nomes foram transcritos como figuram no documento. Embora a relação de bolsistas divida os financiados pelo IHB e pela DME, uma análise das fichas de bolsistas indica que os nomes de Simeão Bomfim e Afrânio do Amaral encontram-se na coluna errada. Já os médicos Carlos Pinheiros Chagas e Álvaro de Lemos Torres possuem fichas de bolsistas tanto do IHB quanto da DME.
} 
Quadro 1 - Bolsas para estudos no exterior aprovadas

\begin{tabular}{|c|c|}
\hline International Health Board & Division of Medical Education \\
\hline Antonio Luis Barreto & Afrânio do Amaral \\
\hline Simeão Bomfim & Ernesto de Souza Campos \\
\hline Sebastiáo Calazans & Carlos Pinheiro Chagas \\
\hline José Alves de Castilho & Euvaldo Diniz Gonçalves \\
\hline Fernando Freitas e Castro & Álvaro de Lemos Torres \\
\hline Olympio da Fonseca & José Baeta Vianna \\
\hline Arminio Fraga & \\
\hline Jorge Dutra Fragoso & \\
\hline Octavio Gonzaga & \\
\hline Octavio Pinto Guedes & \\
\hline José de Carvalho Lima & \\
\hline Waldomiro de Oliveira & \\
\hline José Costa Pinto & \\
\hline José Toledo Piza & \\
\hline Paulo Proença & \\
\hline G. H. de Paula Souza & \\
\hline Francisco Borges Vieira & \\
\hline
\end{tabular}

Fonte: Strode para Wells, 23 maio 1925

Em reflexão sobre o papel desempenhado pelos dirigentes médicos locais que participaram das campanhas da Fundação Rockefeller (o que também envolveu alguns dos ex-bolsistas), Cueto e Palmer (2016, p. 129) consideram que eles não trabalhavam apenas para seu governo ou para uma instituiçáo norte-americana. Desempenhavam, em certo momento, um papel paradoxal de agentes triplos, que prestavam lealdade às metas definidas em Nova Iorque, promoviam a agenda política local de saneamento e educação e buscavam construir uma rede internacional de ciência e saúde.

\section{Considerações finais}

A análise das trajetórias de bolsistas da Fundação Rockefeller, com ênfase em profissionais que se formaram no Instituto Oswaldo Cruz, auxilia na reflexão sobre as interaçóes médicas realizadas entre Brasil e Estados Unidos para a disseminação de um modelo específico de saúde pública. Mais do que isso, demonstra os processos, os conflitos e as imprevisibilidades presentes desde a seleção até o retorno desses atores sociais ao Brasil para compor projetos sanitários.

Em contraposição a uma visão linear, que poderia conceber as viagens dos bolsistas a partir de critérios preestabelecidos e rigidamente cumpridos, foi possível observar que, em 
relação aos anos aqui estudados, as próprias normas de seleção de bolsistas ainda se encontravam em formataçáo e variavam de acordo com aspectos da vida cotidiana dos homens escolhidos e do contexto político-sanitário do país. Assim, tornam-se visíveis particularidades locais que implicaram em trajetórias que compóem a saúde internacional, seja pelas disputas de poder no Comitê Consultivo, pelo adiamento de uma bolsa para conseguir um emprego público efetivo, ou mesmo pela morte antes da viagem, como ocorreu com João Florêncio Salles Gomes. Tornar-se um brasileiro bolsista da Fundaçáo Rockefeller, entre 1919 e 1924, dependia de uma interaçáo entre as expectativas do IHB e as realidades locais dos candidatos.

O IOC desempenhou um papel importante para a formação dos médicos aqui apresentados, pois foi responsável pela sua introdução em uma rotina de formação profissional voltada para a medicina experimental e para a bacteriologia. Com uma formação que enfatizava o trabalho em laboratório e com o apoio de Carlos Chagas, que também encontrava raízes ali, conseguiu enviar profissionais, que passaram por aquele ambiente institucional para a formaçáo internacional.

No exterior, os médicos podiam estudar temas de seu interesse, desde que realizassem o curso da Johns Hopkins, conforme demonstram as trajetórias de Fraga e Barros Barreto. A relação entre brasileiros e norte-americanos não se deu de cima para abaixo, numa dicotomia entre "centro" e "periferia", como já analisado por outros autores (BIRN, 2006; CUETO; PALMER, 2016). Pelo contrário, é possível perceber interaçóes, circulação de conhecimentos e de experiências, em relações que compõem os caminhos seguidos pela saúde internacional.

\section{Fontes documentais}

ALB. Academia de Letras da Bahia. Antônio Luis Cavalcanti de Albuquerque de Barros Barreto. Fundo dos Acadêmicos Falecidos. Arquivo Renato Berbert de Castro. Cadeira 5, 20 Titular, Biografia, pasta 59. 1947.

ALUNOS do curso de Aplicação de 1912. Disponível em: http://arch.coc.fiocruz.br/index. php/alunos-do-curso-de-aplicacao-de-1912. Acesso em: 19 fev. 2020.

BARRETO, Antônio Luis Cavalcanti de Albuquerque de Barros. Relatório da Secretaria de Saúde e Assistência Pública: anno de 1926. Bahia: Imprensa Oficial do Estado, 1927.

BARRETO, Antônio Luis Cavalcanti de Albuquerque de Barros. RG 10.2 (Fellowship Recorder Cards), Series MNS (Medical and Natural Sciences Brazil), s.d.

BARRETO, Antônio Luis Cavalcanti de Albuquerque de Barros. The action of X-rays on basal matabolism. Thesis (Degree of Doctor of Health Public) - Public Health, School of Hygiene and Health Public, Johns Hopkins University, Baltimore, EUA, 15 maio 1922.

CHAGAS, Carlos. [Correspondência]. Destinatário: Wickliffe Rose. 26 set. 1919. RAC, RF 
records, IHB, RG 5, Series 1, FA115, Box 78, Folder 1111.

FONSECA FILHO, Olympio Oliveira Ribeiro da. Olympio da Fonseca (depoimento 1977). Rio de Janeiro: CPDOC, 2010.

FRAGA, Armínio. RG 10.2 (Fellowship Recorder Cards), Series MNS (Medical and Natural Sciences Brazil), s.d.

HACKETT, Lewis. [Correspondência]. Destinatário: Victor George Heiser. 11 mar. 1921. RAC, RF records, IHB, RG 5, Series 2, FA115, Box 24, Folder 144.

HACKETT, Lewis. [Correspondência] Destinatário: Richard Pearce. 17 dez. 1919. RAC, RF records, IHB, RG 5, Series 1, FA115, Box 78, Folder 1110.

HACKETT, Lewis. [Correspondência]. Destinatário: Wickliffe Rose. 26 fev. 1919. RAC, RF records, IHB, RG 5, Series 1, FA115, Box 78, Folder 1109.

HACKETT, Lewis. [Correspondência]. Destinatário: Wickliffe Rose. 14 jun. 1921. RAC, RF records, IHB, RG 5, Series 1, FA115, Box 113, Folder 1535.

HACKETT, Lewis. [Correspondência]. Destinatário: Wickliffe Rose. 3 abr. 1919. RAC, RF records, IHB, RG 5, Series 1, FA115, Box 78, Folder 1109.

HACKETT, Lewis. [Correspondência]. Destinatário: Wickliffe Rose. 31 dez. 1920. RAC, RF records, IHB, RG 5, Series 1, FA115, Box 95, Folder 1307.

HACKETT, Lewis. [Correspondência]. Destinatário: Wickliffe Rose. 5 ago. 1920. RAC, RF records, IHB, RG 5, Series 1, FA115, Box 95, Folder 1307.

HACKETT, Lewis. [Correspondência]. Destinatário: Wickliffe Rose. 5 jun. 1919. RAC, RF records, IHB, RG 5, Series 1, FA115, Box 78, Folder 1109.

HACKETT, Lewis. [Correspondência]. Destinatário: Wickliffe Rose, 6 mai. 1921. RAC, RF records, IHB, RG 5, Series 1, FA115, Box 113, Folder 1535.

HACKETT, Lewis. [Correspondência]. Destinatário: Wickliffe Rose. 7 abr. 1919. RAC, RF records, IHB, RG 5, Series 1, FA115, Box 78, Folder 1109.

HACKETT, Lewis. [Correspondência]. Destinatário: Clifford Wells. 14 out. 1921. RAC, RF records, IHB, RG 5, Series 1, FA115, Box 113, Folder 1536.

HACKETT, Lewis. [Correspondência]. Destinatário: Clifford Wells 4 jan. 1921a. RAC, RF records, IHB, RG 5, Series 1, FA115, Box 113, Folder 1534.

HACKETT, Lewis. [Correspondência]. Destinatário: Clifford Wells. 4 jan. 1921b. RAC, RF records, IHB, RG 5, Series 1, FA115, Box 113, Folder 1534.

HEISER, Victor George. [Correspondência]. Destinatário: Lewis Hackett. 22 mai. 1919. RAC, RF records, IHB, RG 5, Series 1, FA115, Box 78, Folder 1109.

HEISER, Victor George. [Correspondência]. Destinatário: Lewis Hackett. 7 jan. 1920. RAC, RF records, IHB, RG 5, Series 1, Box 95, Folder 1307. 
READ, Florence. [Correspondência]. Destinatário: Lewis Hackett. 18 ago. 1921. RAC, RF records, IHB, RG 5, Series 1, FA115, Box 113, Folder 1536.

ROLLIN, Dean [Correspondência]. Destinatário: John Janney. 30 dez. 1926. RAC, RF records, IHB, RG 5, Series 1, FA115, Box 253, Folder 3229.

ROSE, Wickliffe. [Correspondência]. Destinatário: Lewis Hackett. 27 mai. 1921. RAC, RF records, IHB, RG 5, Series 1, FA115, Box 113, Folder 1535.

SECRETARY ASSISTANCE. [Correspondência]. Destinatário: Lewis Hackett. 6 jun. 1921. RAC, RF records, IHB, RG 5, Series 1, FA115, Box 113, Folder 1535.

STRODE, George. [Correspondência]. Destinatário: Clifford Wells. 23 mai. 1925. RAC, RF records, IHB, RG 5, Series 1, FA115, Box 222, Folder 2834.

VALENTE, Jorge. Centros de saúde. Tese (Doutorado em Ciências Médico-Cirúrgicas) Cadeira de Higiene, Faculdade de Medicina da Bahia, Salvador, 1927.

WELLS, Clifford. [Correspondência]. Destinatário: Lewis Hackett. $1^{\circ}$ jun. 1922. RAC, RF records, IHB, RG 5, Series 1, FA115, Box 135, Folder 1794.

WELLS, Clifford. [Correspondência]. Destinatário: Lewis Hackett. 5 abr. 1921. RAC, RF records, IHB, RG 5, Series 1, FA115, Box 135, Folder 1794.

WELLS, Clifford. [Correspondência]. Destinatário: Lewis Hackett. 8 set. 1921. RAC, RF records, IHB, RG 5, Series 1, FA115, Box 113, Folder 1536.

WELLS, Clifford. [Correspondência]. Destinatário: George Strode. 24 ago. 1921. RAC, RF records, IHB, RG 5, Series 1, FA115, Box 113, Folder 1530.

\section{Referências}

AZEVEDO, Nara; Ferreira, Luiz Otávio. Os dilemas de uma tradição científica: ensino superior, ciência e saúde pública no Instituto Oswaldo Cruz, 1908-1953. História, Ciências, Saúde - Manguinhos, Rio de Janeiro, v. 19, n. 2, p. 581-610, abr.-jun. 2012.

BATISTA, Ricardo dos Santos. A formação inicial de Antônio Luis Cavalcanti de Albuquerque de Barros Barreto: uma trajetória rumo à saúde internacional. História, Ciências, Saúde Manguinhos (Rio de Janeiro), v. 26, n. 3, p. 801-822, jul-set. 2019a.

BATISTA, Ricardo dos Santos. Educação e propaganda sanitárias: desdobramentos da formação de um sanitarista brasileiro na Fundação Rockefeller. História, Ciências, Saúde Manguinhos (Rio de Janeiro), v. 26, n. 4, p. 1189-1202, out.-dez. $2019 \mathrm{~b}$.

BATISTA, Ricardo dos Santos. Siflis e reforma da saúde na Bahia. Salvador: Eduneb, 2017. BENCHIMOL, Jaime Larry (coord.). Febre amarela: a doença e a vacina, uma história 
inacabada. Rio de Janeiro: Ed. Fiocruz, 2001.

BENCHIMOL, Jaime Larry; TEIXEIRA, Luiz Antônio. Cobras, lagartos \& outros bichos: uma história comparada dos institutos Oswaldo Cruz e Butantan. Rio de Janeiro: Editora UFRJ, 1993.

BIRN, Anne-Emanuelle. Marriage of convenience: Rockefeller international health and revolutionary Mexico. University of Rochester Press, 2006.

BYNUM, William. História da medicina. Tradução de Flávia Souto Maior. Porto Alegre: L\&PM Pocket, 2011.

CAMPOS, Cristina de. A viagem de Geraldo Paula Souza para os Estados Unidos, 19181920: fragmentos de uma história da relação entre a Fundação Rockefeller e o Instituto de Higiene de São Paulo. In: MARINHO, Maria Gabriela da Silva Martins da Cunha; MOTA, André (orgs.). Caminhos e trajetos da filantropia científica em São Paulo: a Fundação Rockefeller e suas articulações no Ensino, Pesquisa e Assistência para a Medicina e Saúde (1916-1952). São Paulo: USP, Faculdade de Medicina: UFABC, Universidade Federal do ABC: CD.G Casa de Soluçóes e Editora, 2013. p. 37-56.

CAMPOS, Cristina de. São Paulo pela lente da higiene: as propostas de Geraldo Horácio de Paula Souza para a cidade (1925-1945). São Carlos: Rima, 2002.

CASTRO SANTOS, Luiz Antônio de; FARIA, Lina Rodrigues. A reforma sanitária no Brasil: ecos da Primeira República. Bragança Paulista: Edusf, 2003.

CATANI, Afrânio Mendes et al. Vocábulário Bourdieu. Belo Horizonte: Autêntica, 2017.

CORTES, Bianca Antunes. Mestres e aprendizes: a iniciação do cientista, em Manguinhos, nos tempos de Oswaldo - 1900-1915. Dissertação (Mestrado em Educação) - Centro de Estudos Sociais Aplicados, Universidade Federal Fluminense, 1993.

CUETO, Marcos (ed.). Missionaries of Science: The Rockefeller Foundation and Latin America. Bloomington: Indiana University Press, 1994.

CUETO, Marcos; PALMER, Steven. Medicina e saúde pública na América Latina: uma história: Rio de Janeiro: Ed. Fiocruz, 2016.

FARIA, Lina. Os primeiros anos da Reforma Sanitária no Brasil e a atuação da Fundação Rockefeller (1915-1920). Physis - Revista de Saúde Coletiva, v. 5, n. 1, 1995.

FARLEY, John. To cast out disease: a history of the International Health Division of the Rockefeller Foundation (1915-1951). Oxford: Oxford University Press, 2004.

FEE, Elizabeth. Disease and Discovery: a History of the Johns Hopkins School of Hygiene and Public Health, 1916-1939. Baltimore: The Johns Hopkins University Press, 2016.

FOSDICK, Raymond B. The story of the Rockefeller Foundation. New York: Routledge, 2017. HOCHMAN, Gilberto. Logo ali, no final da avenida: os sertóes redefinidos pelo movimento sanitarista da Primeira República. História, Ciências, Saúde-Manguinhos, Rio de Janeiro, v. 
5, supl., p. 217-235, 1998.

KORNDÖRFER, Ana Paula. “An international problem of serious proportions”: a cooperação entre a Fundação Rockefeller e o Governo do Estado do Rio Grande do Sul no combate à ancilostomíase e seus desdobramentos (1919-1929). Tese (Doutorado em História) Pontifícia Universidade Católica do Rio Grande do Sul, Porto Alegre, 2013.

MARINHO, Maria Gabriela Silva Martins da Cunha. Elites em negociação: breve história dos acordos entre a Fundação Rockefeller e a Faculdade de Medicina de São Paulo (19161931). In: MARINHO, Maria Gabriela Silva Martins da Cunha; MOTA, André (orgs.). Caminhos e trajetos da filantropia cientifica em São Paulo: a Fundação Rockefeller e suas articulaçóes no ensino, pesquisa e assistência para a medicina e saúde (1916-1952). São Paulo: USP, Faculdade de Medicina: UFABC, Universidade Federal do ABC: CD.G Casa de Soluçóes e Editora, 2013. p. 81-175.

MARQUES, Rita de Cássia; SILVEIRA, Anny Jackeline Torres. Baeta Vianna, o laboratório de bioquímica e a Fundação Rockefeller na Faculdade de Medicina de Belo Horizonte (1913-1964). In: MARINHO, Maria Gabriela Silva Martins da Cunha; MOTA, André; CAMPOS, Cristina de. Racionalidades em disputa: intervençôes da Fundação Rockefeller na ciência, medicina e práticas médicas do Brasil e América Latina. São Paulo: USP, Faculdade de Medicina: UFABC, Universidade Federal do ABC: CD.G Casa de Soluçóes e Editora, 2015. p. 35-53.

THIELEN, Eduardo Vilela et al. A ciência a caminho da roça: imagens das expediçóes científicas ao interior do Brasil entre 1911 e 1913. Rio de Janeiro: Ed. Fiocruz, 2002. 